\title{
ARTICLE
}

Epidemiology and Population Health

\section{Data visualisation to support obesity policy: case studies of data tools for planning and transport policy in the UK}

\author{
Pablo Monsivais $\mathbb{1}^{1,2} \cdot$ Oliver Francis ${ }^{1} \cdot$ Robin Lovelace $\mathbb{1}^{3} \cdot$ Michael Chang ${ }^{4,5} \cdot$ Emma Strachan $^{6} \cdot$ \\ Thomas Burgoine $\mathbb{B}^{1}$
}

Received: 4 June 2018 / Revised: 14 September 2018 / Accepted: 21 October 2018 / Published online: 23 November 2018

(c) The Author(s) 2018. This article is published with open access

\begin{abstract}
Data visualisation is becoming an established way to drive discovery and develop theory and hypotheses among researchers. Data visualisations can also serve as tools for knowledge translation with policy makers, who are increasingly using data and evidence to inform and implement policy. For obesity policy, data visualisation tools can help policy makers and other professionals understand the socio-spatial distribution of risk factors and quantify social and environmental conditions that are recognised upstream determinants of diet, activity and obesity. The demand for and use of data visualisation tools can be driven by an identified policy need, which can be met by researchers and data scientists. Alternatively, researchers are developing and testing data visualisations, which may be subsequently adapted for, and adopted by policy users.
\end{abstract}

Two recently-released interactive data visualisation tools in the UK illustrate these points. The Propensity to Cycle Tool (PCT) was developed with funding from the UK government to inform the investment of cycling infrastructure in England. The Food environment assessment tool (Feat) evolved as a translational output from a programme of epidemiological research. This article uses PCT and Feat as case studies, drawing parallels and contrasts between them. We discuss these two tools from policy context and scientific underpinnings, to product launch and evaluation. We review challenges inherent in the development and dissemination of data tools for policy, including the need for technical expertise, feedback integration, long-term sustainability, and provision of training and user support. Finally, we attempt to derive learning points that may help overcome challenges associated with the creation, dissemination and sustaining of data tools for policy. We contend that, despite a number of challenges, data tools provide a novel gateway between researchers and a range of stakeholders, who are seeking ways of accessing and using evidence to inform obesity programs and policies.

Pablo Monsivais

p.monsivais@wsu.edu

1 UKCRC Centre for Diet and Activity Research (CEDAR), MRC Epidemiology Unit, University of Cambridge School of Clinical Medicine, Institute of Metabolic Science, Cambridge Biomedical Campus, Cambridge CB2 0QQ, UK

2 Department of Nutrition and Exercise Physiology, Elson S. Floyd College of Medicine, Washington State University, Spokane, WA 99210, USA

3 Institute for Transport Studies, University of Leeds, Leeds LS2 9JT, UK

4 Town \& Country Planning Association, London SW1Y 5AS, UK

5 Carnegie School of Sport, Leeds Beckett University, Leeds LS6 3QT, UK

6 Health Improvement, Leeds City Council, Leeds LS2 9JT, UK

\section{Background}

Obesity is both a public health crisis and a scientific challenge. Within the last 40 years, the prevalence of obesity in the UK has nearly quadrupled, from $6-8 \%$ of the adult population in 1980 to $26 \%$ today [1,2], costing to the public purse in England an estimated $£ 27$ billion per year [3]. The volume of obesity research has undergone an even more dramatic increase over the same period, from roughly 1200 articles published in 1980 to over 21,000 articles published in 2017 alone. This scientific momentum has brought with it innovation of data sources and analytical approaches. While the visual representation of data, for instance, in charts and other graphics, has long been integral to the scientific process [4], scientific innovations and use of 'big data' in particular have driven new ways of visualising data. Data visualisations are important for communicating to scientific 
audiences, and increasingly an essential component of disseminating complex research findings to the public, and helping to better inform policy development. Moreover, the urgent societal implications of obesity are challenging researchers to carefully consider the potential of data visualisations to better serve public policy and practice.

\section{What are data visualisations?}

Data visualisation is commonly defined as a graphical approach to the presentation of data. Data visualisation can make data more accessible by providing an opportunity to examine and explore large amounts of often complex, quantitative information at once [5]. Although this broad definition of data visualisation includes scientific illustrations and figures, these are targeted at academic or otherwise specialist audiences, and so do not realise the full potential of data visualisation, which also includes interactivity and flexible outputs for users. Furthermore, some researchers, particularly those from computing- and graphics-intensive disciplines, have advocated the use of data visualisations not just as an output or adjunct of research but as a complement to traditional statisticallybased approaches to exploring data, developing theory and testing hypotheses [6].

\section{Data visualisation for obesity research}

Since the publication of the Foresight report in 2007 [7], there has been growing recognition that obesity results from the interplay of multiple biological, behavioural and social determinants within a complex system $[8,9]$. The complex, multifactorial nature of population-level obesity poses a challenge to the prevailing theoretical and analytic paradigms commonly used in human obesity research [10].

In obesity epidemiology, statistical approaches to understanding associations and putative causal factors have been increasingly complemented by visual approaches. For example, among biological determinants of obesity, genetics account for $40-70 \%$ of the population variance in obesity susceptibility [11]. Genome-wide association studies, visualised with Manhattan plots (Fig. 1a), have allowed researchers to identify genetic variants at numerous loci that are strongly associated with obesity and common metabolic diseases [12]. Obesity also has strong social determinants, and social scientists have used Barabasi-Albert network visualisations (Fig. 1b) to identify clusters of obese adults within a social network, and over time [13]. These two examples illustrate the usefulness of data visualisation to systematise and explore large amounts of empirical big

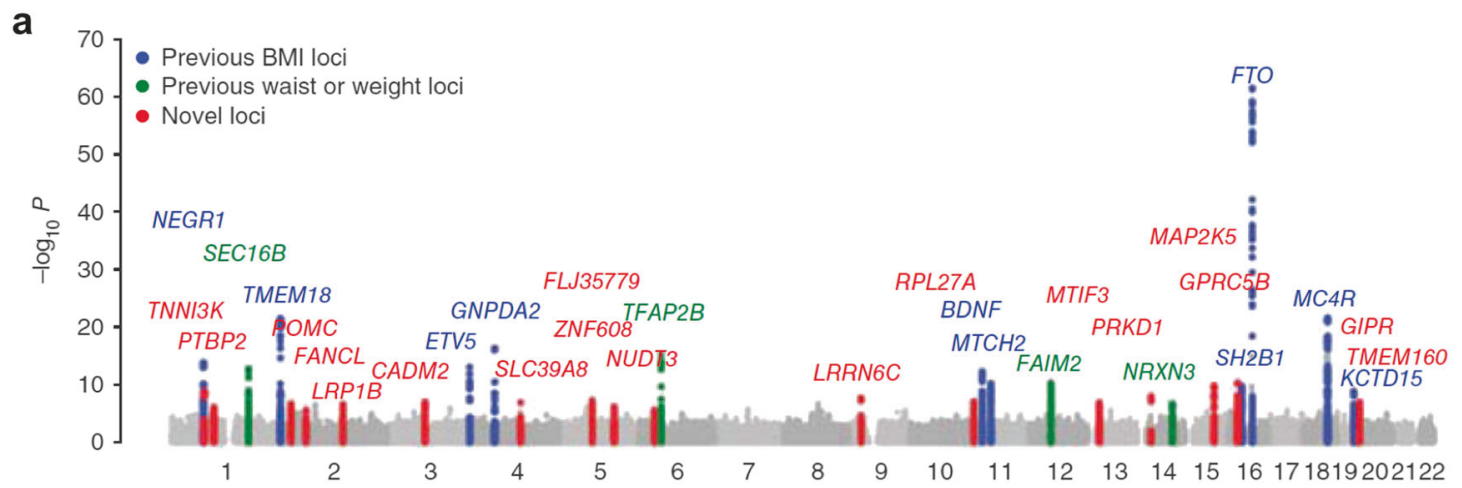

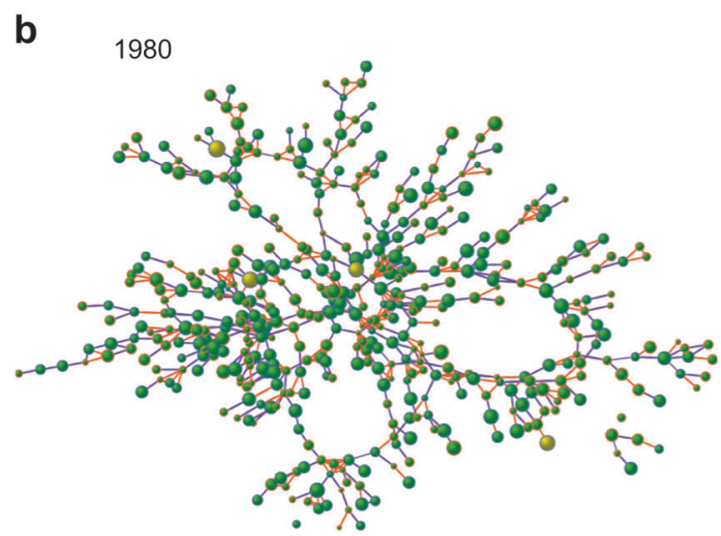

Fig. 1 a, b Examples of data visualisations used in population-level obesity research. A Manhattan plot used for identifying genetic loci associated with obesity (a) (From reference [12], reprinted with

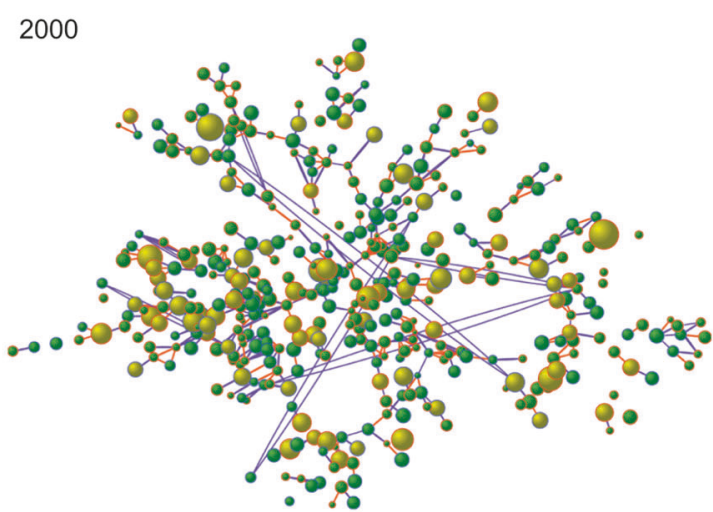

permission of the authors.) A network diagram for identifying social relationships among obese and non-obese members of a community (b) (From reference [13], reprinted with permission of the authors.) 
data'. Data visualisation can also facilitate knowledge exchange and translation for policy [14].

\section{Data visualisation for policy}

Big data and other large, routine data sets have the potential to support decision-making and policy, particularly when presented geographically [15]. Data to inform public health priorities and action at local and smaller geographic levels are increasingly available. In the UK, data visualisations and other data-based tools feature prominently in Public Health England's (PHE's) Knowledge Strategy [16]. The development and dissemination of such tools, in addition to the standardisation, structuring and linkage of the data and systems underlying them, provides a means of supporting decision making and informing policy and practice across public health [16]. For example, Fingertips [17] provides a public access interface for data on disease burden, risk factors and other population health indicators for England, at various levels of geographic specificity. Data on obesity prevalence in the adult population can be retrieved and stratified by a number of sociodemographic characteristics, as well as reported and displayed geographically [18]. The platform also allows users to compare prevalence for one group or within one area against the national average or against other groups or areas. Some regions in the UK are developing similar capabilities. The Leeds Observatory hosts a wide range of economic, social and health indicators for the region, at various levels of geography [19].

An important feature of both Fingertips and the Leeds Observatory tools is their capacity to display data in tabular format as well as in a range of graphics that facilitate comparisons between social groups and between regions. These graphics include choropleth maps (spatial data visualisations), which use colour or shading to convey differences in disease rates or risk factors in a way that is easily recognisable and intuitive. Spatial data visualisations can facilitate analysis at a range of geographic scales that are relevant for policy, for example by providing estimates at the level of local government administrative boundaries. Whilst available to everyone on the Internet, Fingertips is intended to help local authorities identify populations and areas that may benefit from intervention.

\section{Data for obesity policy}

Four important trends have converged to increase the importance of local data for decision-making for obesity prevention within local government. First, with the Health and Social Care Act of 2012, the responsibility for public health moved from the National Health Service's Primary Care Trusts into local governments, which were given the authority to set priorities and policy independently [20]. Second, both local and national policy makers are increasingly complementing individually-targeted obesity programs with population-level interventions that are local context specific [21, 22]. Thirdly, the National Planning Policy Framework, which sets the overall planning guidance for local government in England, requires local health needs to be taken into account when developing planning policies [23]. Finally, there has been an increasing scientific focus on upstream determinants of disease (including obesity), which often vary locally [9]. Moreover, there is a growing recognition of the multiple avenues by which population-level determinants of obesity can be addressed, including through cross-sectoral policy, systems and environmental action [24], including planning and transport policy.

Planning and transport policies are two promising areas relevant for obesity because they represent the potential to build and modify aspects of the built environment that can improve population diet and physical activity. Since the 1990s, efforts to promote active travel have been part of the UK national transportation strategy, with a focus on reducing congestion, improving air quality and improving accessibility [25]. While the national approach to transport planning continues to be set by central government, specific decisions about pedestrian and cycle infrastructure are being made by local authorities. With regards to diet, local governments have long been responsible for considering planning applications for the establishment of food retail outlets, but in the last 10 years, this authority has come to be seen as a possible point of public health intervention, with the potential to improve the healthfulness of the food environment. For example, both local governments and PHE have advocated for the use of planning powers to limit the proliferation of fast-food outlets in towns and cities [26].

Historically, there has been little in the way of easily accessible data available to guide local decision making with the potential to encourage active transport and healthier dietary behaviour. Below, we outline two case studies, of tools recently developed by ESRC Strategic Network for Obesity members at the Centre for Diet and Activity Research (CEDAR), which use spatial data visualisation as a platform to support local decision making. After briefly describing each tool, the main aim of this manuscript is to draw from these case studies examples of generalised learning experiences and challenges, while highlighting important implications for research and policy. The key characteristics of these tools, including brief technical details, are presented in Table 1. This paper is not intended to provide a detailed technical description of each tool. For further description of the more technical aspects of PCT, see Lovelace et al. [27]. Technical aspects of Feat will be described in a forthcoming publication. 
Table 1 Key characteristics of two data visualisation tools for policy

Propensity to Cycle Tool (PCT)

Food environment assessment tool (Feat)

Administrative

URL

www.pct.bike

May 2015 (prototype)

March 2017 (official launch)

Region(s) covered

Funding source(s)

Externally commissioned?

Hosting institution

Update frequency

Historic data available

Technical

Key output data

Software

Basemap

Geographic display levels

Input environmental data, source

Input behavioural data, source

Other data, source

User modifiable through open

source code?

Other

Data access

User support contact
England, Wales

UK DfT

\section{Yes, by UK DfT}

Mythic Beasts via Cambridge, Westminster and Leeds Universities

Approximately yearly

No

Cycle network maps

$\mathrm{R}$ (packages: shiny, leaflet, stplanr)

Open Street Map

Area (MSOA, LSOA), Desire line, route, street network

OpenStreetMap; Origin-Destination data, routing from CycleStreets.net

UK Travel Survey, Dutch Travel Survey

Population, 2011 UK census

Yes, https://github.com/npct/pct-shiny www.feat-tool.org.uk

July 2017

England

ESRC Impact Acceleration Account and University of Cambridge MRC Epidemiology Unit

No

MRC Epidemiology Unit, University of Cambridge

Quarterly

Yes

Density and mix of food outlets

ArcGIS, Leaflet

Open Street Map

County, Local authority, MSOA, LSOA, ward, unit postcode

Food outlets, Ordnance Survey Points of interest; geographic boundaries, UKBORDERS and Ordnance Survey Code-point with Polygons

N/A

Population, 2011 UK census

No

Free data access of all levels in map format only feat-tool@mrc-epid.cam.ac.uk

\section{Case study 1: The Propensity to Cycle Tool}

Active travel (walking and cycling) is an important source of routine physical activity that can be integrated into everyday life as part of a wider sustainable transport system. However, in many countries, private motor vehicles are still the default option, even for short trips, which make-up the majority of trips in countries such as the UK, where the majority $(56 \%)$ of car journeys driven are less than 5 miles [28]. Cycling is a particularly promising transport mode in this context because it has the potential to replace more car trips than walking, with an average distance of 3.5 miles for cycle trips in 2016 compared to an average of only 0.7 miles for walking trips.

Nevertheless, the prevalence of cycling for transportation in the UK is low, with approximately $3 \%$ of journeys being undertaken by bike [29]. International experience shows that high-quality infrastructure can play a key role in promoting cycling uptake [30]. Separated cycle paths, for example, in addition to other elements of cycling infrastructure, have been found to be associated with an uptake of cycling for commuting. But where should this infrastructure be built to yield the greatest impact? It is in this context that the UK's Department for Transport funded development of the Propensity to Cycle Tool (PCT), to provide a publicly-accessible and local evidence-base for planning strategic cycle networks based on routes, corridors and 'desire lines' with high potential for cycling uptake [27, 31].

The project can be divided into three main stages: software testing and development; data analysis; and national deployment. In the development phase, researchers from four universities (Leeds, Cambridge, Westminster and London School of Hygiene and Tropical Medicine) collaborated to develop a prototype web application using Shiny, an $\mathrm{R}$ package for interactive visualisation [32]. An additional $\mathrm{R}$ package was developed for geographical processing and routing on the road network of the input data: origin-destination pairs between commute zones from the 2011 Census. Noteworthy features of the development process were the use of GitHub for code hosting, version control and communication, and the use of 'continuous 

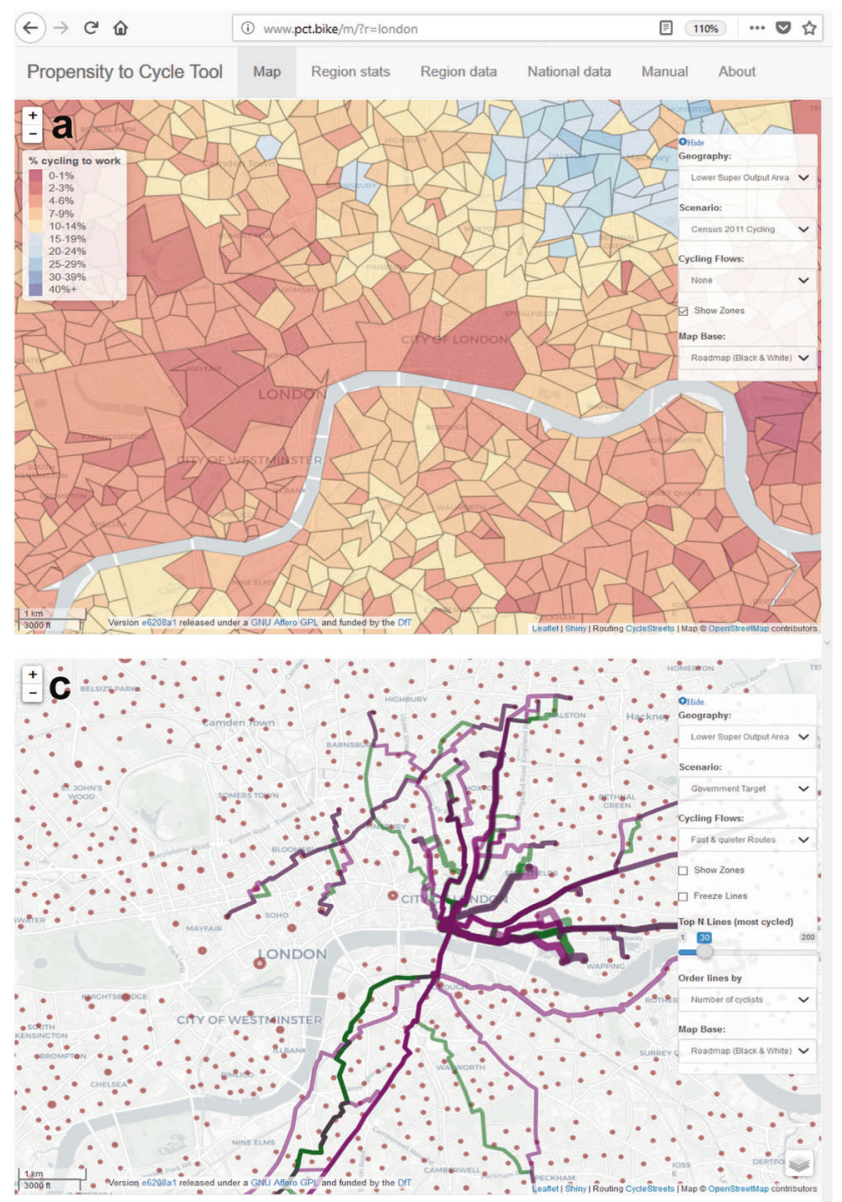

Fig. 2 Screenshots of the PCT show four visualisation layers for central London. Panels (a) and (b) show two scenarios, 'Census 2011 Cycling' and 'Go Dutch' at the small area (LSOA) level. These highlight areas in need of investment in the short-to-long term based

integration' on a test server so all collaborators could comment on the latest version of the tool as it evolved.

In the data analysis stage, scenarios were developed via in-depth analysis of National Travel Surveys in the UK and the Netherlands [31]. The scenarios are an important element of the PCT, allowing stakeholders to visualise what a shift to cycling could look like, in terms of number of commuter cyclists using different parts of a (yet-to-bebuilt) network of protected cycleways taking direct routes to major employment centres. Figure 2 shows four visualisation layers in PCT for central London. Figure 2a and $2 \mathrm{~b}$ show two scenarios, 'Census 2011 Cycling' and 'Go Dutch' at the small area (LSOA) level. These highlight areas in need of investment in the short-to-long term based on current trip patterns. Figure $2 \mathrm{c}$ shows the same area but with the Fast and Quieter Route layers activated to highlight existing routes between the most popular desire lines for cycling under the Government Target scenario, and where they go. Figure $2 \mathrm{~d}$ shows the Route Network layer at the LSOA level, the most
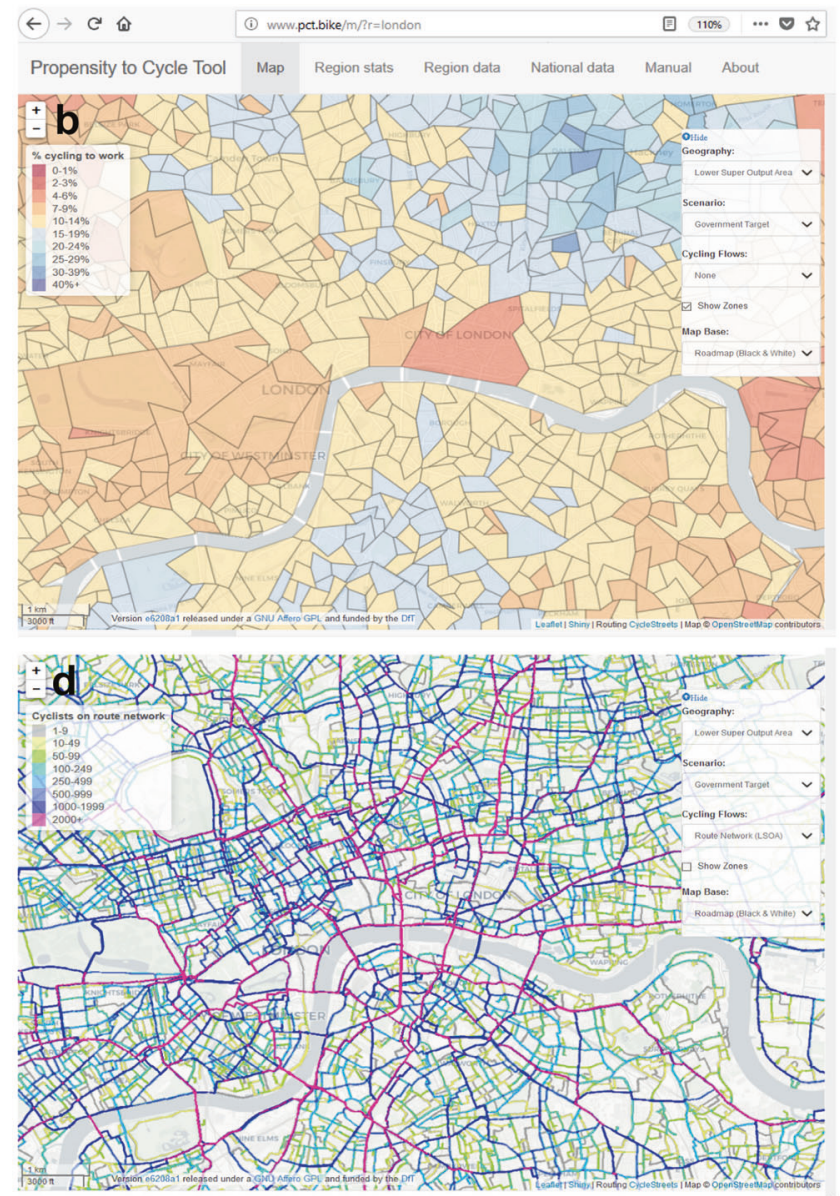

on current trip patterns. Panel (c) shows the same area but with the Fast and Quieter Route layer activated. Panel (d) shows the route Network layer at the LSOA level, the most geographically detailed layer in the PCT

geographically detailed layer in the PCT, which can inform investment in cycle networks down to the street network nationwide.

The final deployment phase was the most important in terms of policy impact. Unusually for an academic project, this involved setting-up a physical server with a dedicated web hosting company and hiring an independent web developer. Before the PCT was officially launched in Spring 2017, a process of user feedback was used to improve the tool for the target audience of local authorities, which included approximately 100 test-users at 12 usertesting workshops held at key events, such as Cycle City Active City (CCAC). These users provided feedback that was incorporated into the version that was later launched.

After launch, the PCT has already begun to realise impact; we know of four local authorities (Transport for Greater Manchester, Merseyside, Warrington, Exeter) who have designed strategic cycle networks based at least in part on the results of the PCT, and it has enabled cycling advocates and other local stakeholders to be engaged in the 
debate, using high-quality information, to envisage healthier transport systems across the UK.

\section{Case study 2: The Food environment assessment tool}

Neighbourhood food environments- the distribution, density and mix of accessible food outlets-are a recognised influence on what we eat, our body weight and health [3]. As a result, published guidelines from PHE (PHE), the Local Government Association (LGA) and the Greater London Authority (GLA) provide strong support for local authorities to, for example, influence the food environment to promote and support healthier food choices [26]. In 2017, PHE also released their 'Out of home food provision toolkit' as part of a population-level approach to obesity prevention [22]. The toolkit cites the need to take local action, and to understand the local food environment. A determining factor in the development of effective policy is strong supporting evidence.

While health researchers have developed a number of methods to assess the food environment, little of this knowledge has been translated for the purpose of environmental assessment by practitioners and policymakers. Some local authorities have conducted one-off, bespoke food environment assessments locally [33], but a comprehensive platform for objective, nationwide surveillance of food access that can be used both nationally and locally, has been critically lacking in England.

The Food environment assessment tool (Feat) was developed to address this need, informed by research evidence. Feat is an interactive, web-based resource for mapping, measuring and monitoring regional and neighbourhood food access across England and over time (see Figure 3). Developed with funding from the Economic and Social Research Council's Impact Acceleration Account, along with in-kind funding from the MRC Epidemiology Unit at the University of Cambridge, Feat was intended to translate the findings of our state-of-the-art scientific evidence, for use by those in planning, environmental and public health within local authorities, regional and national public health bodies.

Feat was developed by an interdisciplinary team of researchers and technicians with expertise in epidemiology, geography, data management, web-based programming and knowledge exchange, based entirely within a single academic department. Feat was developed through an iterative process of creating and releasing a minimum viable product for testing, receiving feedback (including further canvassing of demand), and refining before releasing the next version. At no point was the development team hoping to release the perfect version of Feat; only one that was good enough to be released, tested and learned from — an approach endorsed in UK policy approaches to online service delivery [34]. The first fully-functional version of Feat (Feat alpha) was launched in April 2016, exclusively to multiple groups of stakeholders from across policy and practice in England. Each of the stakeholder groups, including 63 representatives from across local and national public health and 22 local authorities, agreed to test and evaluate Feat alpha for a period of 6 weeks, and provide structured feedback via email questionnaire. In addition, we sought engagement with key stakeholders through showcasing the Feat alpha in person at several local governments, PHE, and at PHE conferences and other meetings with majority policy and practice audiences.

The feedback we received from this process was used to evaluate Feat's current and potential functionality. The feedback-in the form of Likert and free-text responses, as well as workshops to identify priorities-allowed us to schedule updates with respect to stakeholder demand, culminating in the development of a Feat beta. We also used this process to further gauge demand, principally by way of soliciting possible applications. For example, respondents identified many applications for Feat, including: quantifying the food environment for local planning and making comparisons with other areas; local needs assessments; targeting education or skills-based individual-level interventions according to food environment characteristics; initiating/ influencing cross-departmental obesity prevention strategies; and overall, using Feat alongside or in lieu of existing local food environment indicators in service of the public's health. Four examples of map outputs from Feat that contain spatial data to support these applications, which include those showing information on electoral ward and addresslevel healthy and unhealthy food retail access (which can be quantified using the legend and histogram shown), and the extent to which this access has changed over time, are shown for central London in Figure 3.

Securing additional short-term funding allowed us to develop the Feat beta and cover data licensing costs, which enabled the launch of Feat freely online in July 2017. Feat's launch was publicised by the UK Health Forum, and prelaunch, Feat was signposted for local authorities in PHE and the LGA's Strategies for encouraging healthier 'out of home' food provision. The launch also received significant media coverage, including seven articles (comprising features and a spin-off interactive data visualisation) that emerged from active collaboration with the Guardian newspaper [35, 36]. As further evidence of initial impact, using web analytics we tracked 7000 page views, from 3250 visitors across 61 countries, within the first 5 weeks of Feat being publicly available. We continue to integrate user feedback to guide further iterations of the tool and new funding from the National Institute for Health Research is presently allowing us to build on our relationships with 

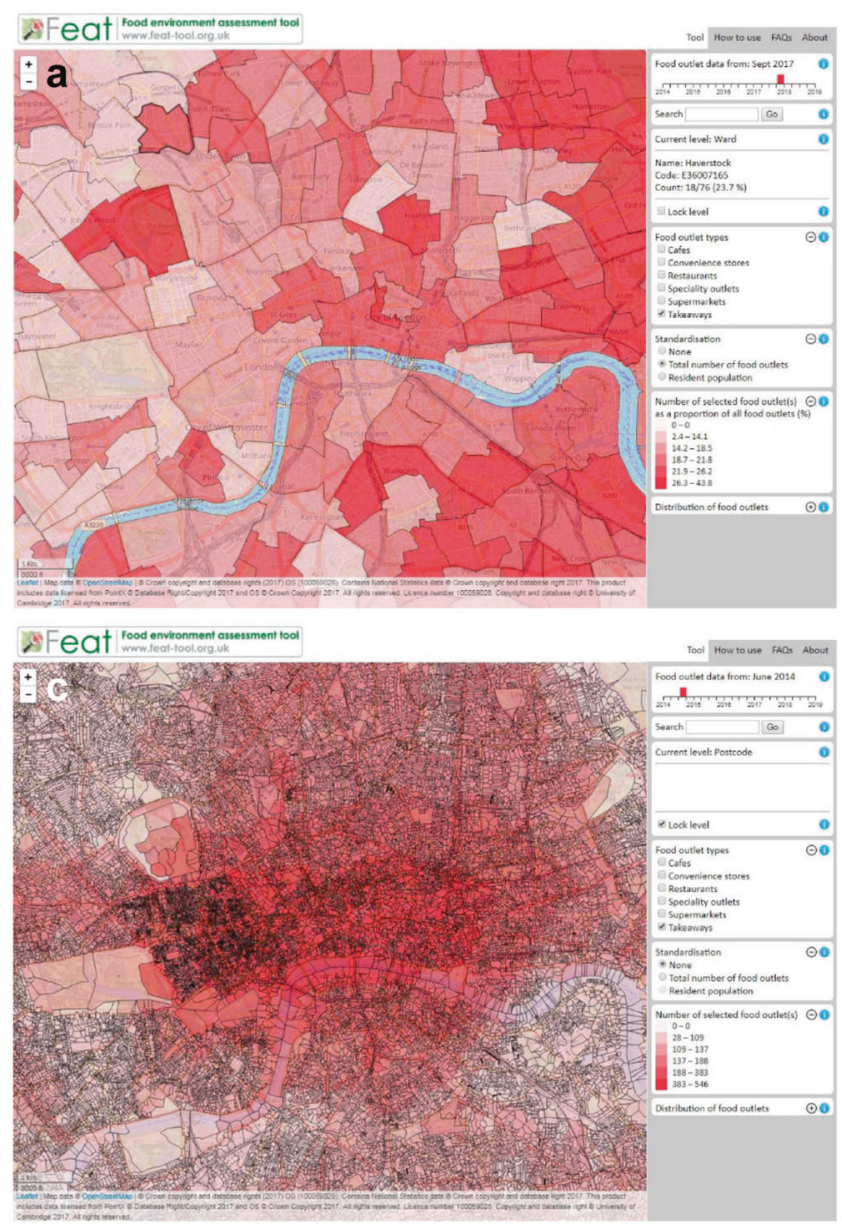

Fig. 3 Illustration of Feat in action in central London: a the user has selected to display an electoral ward level estimate of takeaway food outlet number, as a proportion of all food outlets, for September 2017; b the user has selected to display a postcode level estimate of takeaway food outlet number, as a proportion of all accessible food outlets, for

local government agencies and document case studies of Feat's use in pursuit of public health impact.

\section{Comparing the tools: distinguishing features}

The PCT and Feat are similar in that both display data on environmental risk factors related to obesity. However, they differ in some important ways. First, the tools differ in the fundamentals of what type of data they provide for visualisation. A key output of PCT is an estimation of the latent demand for cycling that could be tapped under various counterfactual scenarios. Alternatively, Feat illustrates quantitative profiles of the food environment, presently and historically. Thus, whereas Feat provides information about 'what is' and 'what was', PCT provides an illustration of 'what if'.

Second, the tools differ in their origins with respect to policy. PCT was driven by an explicit policy imperative: to provide a framework and systematic evidence
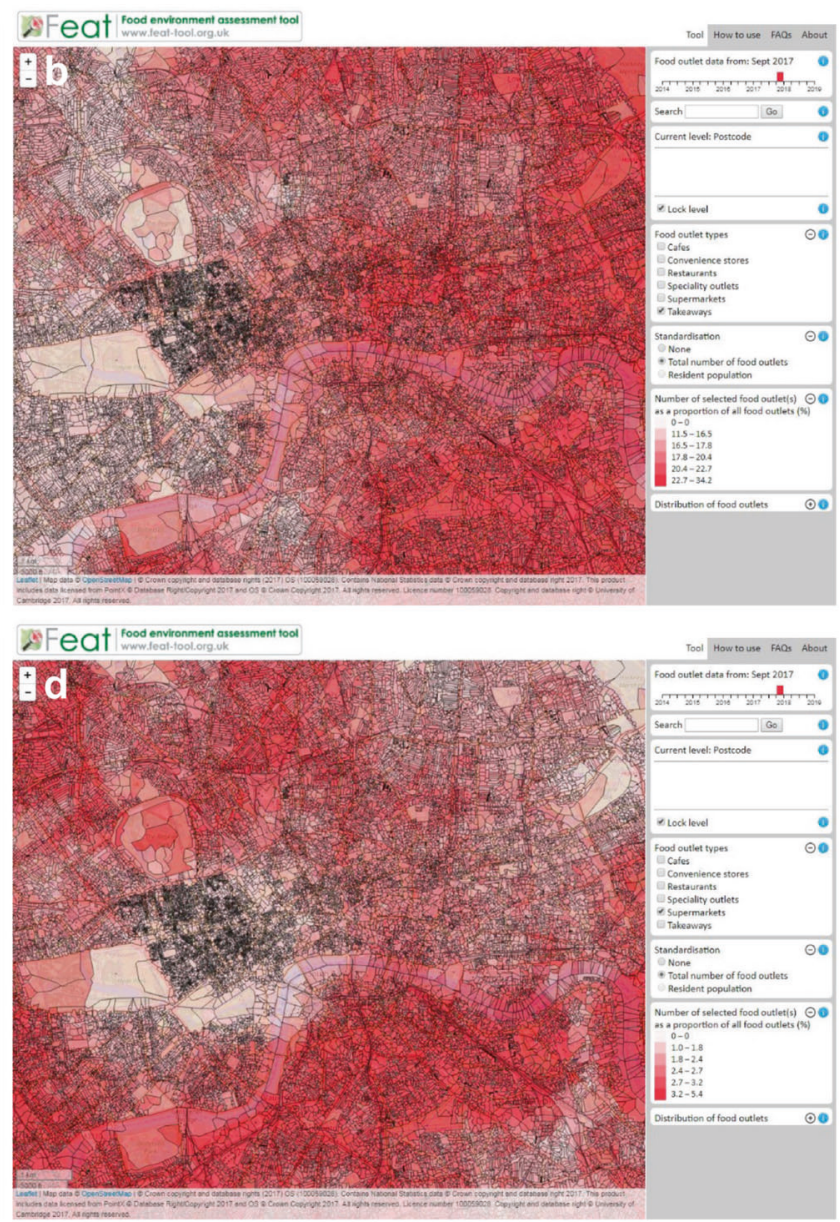

September 2017; c the user has selected to display a postcode level estimate of takeaway food outlet number (unstandardised, raw counts), for June 2014; d the user has selected to display a postcode level estimate of supermarket number, as a proportion of all accessible food outlets, for September 2017

for guiding investment in cycling-related infrastructure across England. This 'pull' from policymakers provided important advantages, particularly in the form of funding, assurance of PCT's place in the policy process, and a guaranteed customer through national level endorsement. In contrast, Feat was developed by researchers as a translational output of an empirical research programme, without any guarantees that the tool would be endorsed or even used by policy-makers and practitioners, and with only short-term funding. This more speculative 'push' model of Feat makes it distinct from the 'pull' model of PCT.

\section{Generalised learning experiences}

From the development of PCT and Feat, we have identified the following common issues and challenges associated with the development of data visualisation tools by 
academics within higher education institutions. This is not intended to be an exhaustive list.

\section{Need for complex and varied skillsets and interdisciplinary working}

Developing data visualisation tools for policy applications related to obesity is a complex, often lengthy process that goes well beyond the usual skillset possessed by academic researchers and departmental support in a higher education setting. Conceptualisation, development, implementation and dissemination of data visualisation tools requires expertise in multiple domains (see Feat case study). For the PCT, lacking expertise in web development meant that an external developer needed to be costed into the project. This may not always be possible, constituting a potential obstacle to progress. Even where skills exist, effective interdisciplinary working will require researchers to engage with and integrate the needs of others into their own ways of working. For example, web development of Feat imposed constraints on the architecture of the input geographic data, requiring the data to be transformed into GeoJSON format [37], previously unfamiliar to the researchers, and requiring new software. These new interdisciplinary ways of working inevitably require both time and patience, but are a critical investment in the long-term viability of most, if not all, interdisciplinary data visualisation tools.

\section{Costs for obtaining data and serving tool}

Beyond the personnel and other costs associated with developing data visualisation tools, there are ongoing costs to maintaining and updating these tools. While many datasets are free to access and use, some, including data that are commercially-sensitive such as Ordnance Survey's Points of Interest data (used in Feat), are not. These costs can be substantial and possibly prohibitive, and challenge traditional academic research funding channels, which are unlikely to be suitable for the purposes of creating tools. It may be difficult to monetise the use of tools, especially where the intended audiences are the public sector. Innovative funding models (e.g. freemium, spin-outs) may be a possibility, although testing can be risky, especially where the tool has previously been available for free.

\section{Identifying the customer and/or policy application}

Research and data of interest to researchers are not necessarily of use to policymakers and practitioners for developing policy or guiding planning decisions. Likewise, data visualisation tools need to include capability that allows these users to answer their own questions of interest-not those of the researchers. This might include, for example, allowing users to manipulate real-world parameters, not just apply fixed hypothetical models. As the Chief Scientific Adviser for the Department of Health and Social Care has observed: 'Models should, wherever possible, allow policymakers to vary assumptions' [38]. A good understanding of the 'market' at which the tool is aimed is therefore necessary-and can be challenging to accurately establish without close existing links to policy customers. It does not follow that there must be a specific demand for the product itself, as the novelty of any tool is likely to be part of its appeal. But the tool should be aimed at a clear user-need that is not being met by current tools and data. Market demand can then be further pinpointed by early release and testing of a minimum viable product. This phase can also help align expectations between users and developers, and attract new potential users not previously identified.

\section{Establishing a strategy for effective dissemination}

As with market research, dissemination is likely to be more effective if the marketing of these tools is part of a wider strategy of stakeholder engagement, which will have already opened up lines of communication between researchers and key users. The PCT and Feat both benefited, to different extents, from the existing dissemination methods and customer networks of their host organisations. A range of stakeholder engagement approaches are needed across social media, news media and interpersonal opportunities (face-to-face meetings, conference and policy forum presentations etc.). Dissemination is also an opportunity to spend social capital that has been built in earlier stakeholder engagement: requests for third-party endorsements, onward promotion by partner organisations and so on.

\section{Tracking engagement and demonstrating impact}

Demonstrating early impact is likely to be a central part of making a compelling case for long-term funding. While engagement with tools can be tracked using straightforward web and social media analytics, these high-level statistics reveal relatively little about tool use and even less about onward application of lessons learned. More sophisticated methods of user tracking and analysis, such as A/B testing and multiple site versions, are more commonly used by commercial companies than academic researchers-often for simple reasons of cost and scale. And even these will be limited to capturing any time users spend directly with the tool Engagement with a tool (a pathway to impact) should not been seen as the same as any eventual impacts that arise following its use, which will be difficult to quantify and may take time to realise. Nevertheless, as part of the wider strategy of stakeholder engagement, it should be possible and sufficient to capture case studies of early use, which are 
important precursors to long-term public health impact. In this sense, the challenges of measuring the impact of these tools shares much with the general challenges of measuring the societal, economic and cultural impact of research: matching approaches to circumstances; considering feasibility and affordability; identifying suitable metrics and measures for both direct and indirect impacts; and applying emerging methods and lessons from what is a developing field [39].

\section{Long-term upkeep and user support}

Many tools are only useful as long as they are kept to date. Where data costs are ongoing, this can prove challenging. Further costs include ongoing work to correct errors and other problems, and continued development to enhance functionality, for example by providing more data options. The online hosting of tools, data management and regular updating of data also carry costs. Some tools, for example the PCT, may also require the upskilling of practitioners in use and application of the tool in their local context, including how the tool could complement and/or build on existing local data and other resources. Options include online or face-to-face training, as well as ongoing one-toone user support for specific applications.

\section{Conclusions}

While the development of some data visualisation products can be externally 'pulled' through policy priorities, others arise because of entrepreneurial researchers working under permissive conditions. Conditions that best enable the development of more-speculative data visualisation tools include a departmental structure that encourages and facilitates communication and collaboration among interdisciplinary teams, together with time and resources to support production and testing. Either way, development of tools presents inevitable challenges, but as a novel pathway to impact, the speculative route may become more common.

As part of the UK's 'Impact Agenda', universities and government research funding bodies are emphasising the need for academics to identify and develop pathways by which their research can have a societal impact [40]. Spatial data visualisation, such as those described here, are one way to address this need. Beyond their use within research programmes, data visualisations can be an important vehicle for reaching, and engaging with wider non-academic audiences [41]. We contend that these tools provide a novel gateway between researchers and a range of stakeholders, policymakers in local and national government in particular, who are increasingly seeking ways of accessing and using evidence to inform obesity programs and policies.
Acknowledgements This article was supported by the ESRC Strategic Network for Obesity, which was funded via Economic and Social Research Council grant number ES/N00941X/1. PM also received support from the Health Equity Research Center at Washington State University. The authors would like to thank all of the Network investigators and members for their participation in Network meetings and discussion which contributed to the development of this paper.

Author contributions PM and TB conceived of the study. PM, TB, $\mathrm{OF}$ and RL drafted the manuscript, with input from MC and EM. All authors contributed considerably to critical revisions and have read and approved the final manuscript.

\section{Compliance with ethical standards}

Conflict of interest The authors declare that they have no conflicts of interest.

Open Access This article is licensed under a Creative Commons Attribution 4.0 International License, which permits use, sharing, adaptation, distribution and reproduction in any medium or format, as long as you give appropriate credit to the original author(s) and the source, provide a link to the Creative Commons license, and indicate if changes were made. The images or other third party material in this article are included in the article's Creative Commons license, unless indicated otherwise in a credit line to the material. If material is not included in the article's Creative Commons license and your intended use is not permitted by statutory regulation or exceeds the permitted use, you will need to obtain permission directly from the copyright holder. To view a copy of this license, visit http://creativecommons. org/licenses/by/4.0/.

\section{References}

1. Tackling obesity in England. 2001. https://www.nao.org.uk/w p-content/uploads/2001/02/0001220.pdf.

2. Statistics on obesity, physical activity and diet. England: Health and Social Care Information Centre; 2017.

3. Public Health England. Health matters: obesity and the food environment. London. 2017. https://www.gov.uk/government/ publications/health-matters-obesity-and-the-food-environment/hea lth-matters-obesity-and-the-food-environment--2 (accessed 3 May 2018).

4. Tufte ER. Visual explanations: images and quantities, evidence and narrative. Cheshire, Connecticut, USA: Graphics Press; 1997

5. Pfitzner D, Hobbs V, Powers D. A unified taxonomic framework for information visualization. Proceedings of the Asia-Pacific symposium on information visualisation. 2003;24:57-66.

6. Fox P, Hendler J. Changing the equation on scientific data visualization. Science. 2011;331:705-8.

7. Butland B, Jebb S, Kopelman P, McPherson K, Thomas S, Mardell J, et al. Foresight tackling obesities: future choicesproject report. Government Office for Science; 2007. p. 1-161.

8. Huang TT, Drewnowski A, Kumanyika SK, Glass TA. A systemsoriented multilevel framework for addressing obesity in the $21 \mathrm{st}$ century. Prev Chronic Dis. 2009;6:1-10.

9. Rutter H, Bes-Rastrollo M, De Henauw S, Lahti-Koski M, Lehtinen-Jacks S, Mullerova D, et al. Balancing upstream and downstream measures to tackle the obesity epidemic: a position statement from the European Association for the Study of Obesity. Obes Facts. 2017;10:61-3. 
10. Savona N, Rutter H, Cummins S. Tackling obesities: 10 years on. 2018;72:93.

11. Elks CE, den Hoed M, Zhao JH, Sharp SJ, Wareham NJ, Loos RJF, et al. Variability in the heritability of body mass index: a systematic review and meta-regression. Front Endocrinol (Lausanne). 2012;3:1-16.

12. Speliotes EK, Willer CJ, Berndt SI, Monda KL, Thorleifsson G, Jackson AU, et al. Association analyses of 249,796 individuals reveal 18 new loci associated with body mass index. Nat Genet. 2010;42:937-50.

13. Christakis NA, Fowler JH. The spread of obesity in a large social network over 32 years. N Engl J Med. 2007;357:370-9.

14. Otten JJ, Cheng K, Drewnowski A. Infographics and public policy: using data visualization to convey complex information. Health Aff. 2015;34:1901-7.

15. MacEachren AM, Gahegan M, Pike W, Brewer I, Cai G, Lengerich E, et al. Geovisualization for knowledge construction and decision support. IEEE Comput Graph Appl. 2004;24:13-7.

16. Public Health England. Knowledge strategy: harnessing the power of information to improve the public's health. London; 2014. https://assets.publishing.service.gov.uk/government/uploa ds/system/uploads/attachment_data/file/320506/PHE_Know ledge_Strategy.pdf.

17. Fingertips Public Health Outcomes Framework. https://fingertips. phe.org.uk/profile/public-health-outcomes-framework/data\#page/ 0 (accessed 3 May 2018).

18. Fingertips User Guide, version 2.1. London; 2016. https:// fingertips.phe.org.uk/documents/UserGuide.pdf.

19. Leeds Observatory: Health and Wellbeing. https://observatory. leeds.gov.uk/health-and-wellbeing/ (accessed 28 May 2018).

20. New focus for public health-The Health and Social Care Act 2012. https://www.gov.uk/government/publications/health-andsocial-care-act-2012-fact-sheets.

21. Making obesity everybody's business: a whole systems approach to obesity. London; 2017. http://www.local.gov.uk/sites/default/ files/documents/15.6 Obesity-05.pdf.

22. Strategies for encouraging healthier 'out of home' food provision: a toolkit for local councils working with small food businesses. London; 2017. https://assets.publishing.service.gov. uk/government/uploads/system/uploads/attachment_data/file/ 604912/Encouraging_healthier_out_of_home_food_provision_ toolkit_for_local_councils.pdf.

23. National Planning Policy Framework. London; 2012. https://www.gov.uk/government/uploads/system/uploads/atta chment_data/file/6077/2116950.pdf.

24. DeSalvo KB, Wang YC, Harris A, Auerbach J, Koo D, O'Carroll P. Public Health 3.0: a call to action for public health to meet the challenges of the 21st Century. Prev Chronic Dis. 2017;14:1-9.

25. Department for Transport. Cycling and walking investment strategy. https://www.gov.uk/government/publications/cycling-a nd-walking-investment-strategy.
26. Public Health England. Obesity and the environment: regulating the growth of fast food outlets. 2013. https://assets.publishing. service.gov.uk/government/uploads/system/uploads/attachment_ data/file/256796/Briefing_Obesity_and_active_travel_final.pdf.

27. National Propensity to Cycle Tool Project: Full Report with Annexes. London; 2016. https://assets.publishing.service.gov.uk/ government/uploads/system/uploads/attachment_data/file/510268/ national-propensity-to-cycle-full-report.pdf.

28. How people travel (mode) (NTS03). Stat. Data Set. 2013. https://www.gov.uk/government/statistical-data-sets/ nts03-modal-comparisons (accessed 28 May 2018).

29. Goodman A. Walking, cycling and driving to work in the English and Welsh 2011 Census: trends, socio-economic patterning and relevance to travel behaviour in general. PLoS One. 2013;8:1-11.

30. Pucher J, Dill J, Handy S. Infrastructure, programs, and policies to increase bicycling: an international review. Prev Med. 2010;50: S106-25.

31. Lovelace R, Goodman A, Aldred R, Berkoff N, Abbas A, Woodcock J. The Propensity to Cycle Tool: an open source online system for sustainable transport planning. J Transp Land Use. 2017;10:505-28.

32. Chang W, Cheng J, Allaire JJ, Xie Y, McPherson J. shiny: Web application framework for R [Computer software]. 2017. http:// CRAN R-project org/package $=$ shiny $(\mathrm{R}$ Packag version 100 ).

33. Developing a physical accessibility standard for healthy food in the West Midlands: Executive Summary. 2009. http://webarchive. nationalarchives.gov.uk/20150116161748/http://www.foodwm. org.uk/resources/Exec_Summary_Final.pdf.

34. How the discovery phase works. Serv. Man. 2017. https://www. gov.uk/service-manual/agile-delivery/how-the-discovery-phase-w orks (accessed 10 May 2018).

35. Butler P. Large rise in takeaway shops highlights dominance of fast food in deprived areas. Guard. 2017. https://www.theguardia n.com/inequality/2017/ju1/25/large-rise-takeaway-shopshighlights-dominance-fast-food-deprived-areas-england.

36. Kommenda N. Fast food England: how many takeaways are near you? 2017. https://www.theguardian.com/inequality/ng-intera ctive/2017/jul/25/fast-food-england-how-many-takeaways-are-nea r-you (accessed 28 May 2018).

37. Butler H, Daly M, Doyle A, Gillies S, Hagen S, Schaub T. The GeoJSON format. 2016.

38. Whitty CJM. What makes an academic paper useful for health policy? BMC Med. 2015;13:1-5.

39. Greenhalgh T, Raftery J, Hanney S, Glover M. Research impact: a narrative review. BMC Med. 2016;14:1-16.

40. Watermeyer R, Chubb J. Evaluating 'impact' in the UK's Research Excellence Framework (REF): liminality, looseness and new modalities of scholarly distinction. Stud High Educ. 2018. https://doi.org/10.1080/03075079.2018.1455082.

41. Shortt NK, Pearce J, Mitchell R, Smith KE. Taking health geography out of the academy: measuring academic impact. Soc Sci Med. 2016;168:265-72. 